\title{
Mediating Effect of Self-Esteem in the Predictive Relationship of Personality and Academic Self-Handicapping
}

\author{
Sau Keng Cheng", Mei Yui Law \\ Faculty of Social Science, Arts and Humanities, Tunku Abdul Rahman University College, Kuala Lumpur, Malaysia
}

Email address:

chengsk@acd.tarc.edu.my (S. K. Cheng), lawmy@acd.tarc.edu.my (M. Y. Law)

To cite this article:

Sau Keng Cheng, Mei Yui Law. Mediating Effect of Self-Esteem in the Predictive Relationship of Personality and Academic Self-Handicapping. American Journal of Applied Psychology. Special Issue: Psychology of University Students.

Vol. 4, No. 3-1, 2015, pp. 51-57. doi: 10.11648/j.ajap.s.2015040301.19

\begin{abstract}
This study was undertaken to examine the predictive relationship between personality traits and academic self-handicapping with self-esteem as the mediator. A total of 62 (19 males, 43 females) Psychology undergraduates participated in the study. Respondents completed a questionnaire that measured their personality, academic self-handicapping and self-esteem. Results revealed that academic self-handicapping has significantly been predicted by neutral personality $(B=-.25, p<0.05)$. Self-esteem mediated the relationship between relational personality and academic self-handicapping. The paths from relational personality to the mediator self-esteem, and sequential to academic self-handicapping were momentous $(\mathrm{B}=.46, \mathrm{p}<0.05 ; \mathrm{B}=$ $-.35, \mathrm{p}<0.05)$. This study has provided implication in which certain personality traits are evident in contributing to different levels of self-esteem and successively self-handicapping behaviors among the undergraduates.
\end{abstract}

Keywords: Personality, Academic Self-Handicapping, Self-Esteem

\section{Introduction}

As reported by Milgram and Tenne [1], personality has significantly been associated with academic procrastination as one of the four types of procrastination. This result has further been supported by the research findings shown in $[2,3,4]$. Among the five types of personality, neuroticism has been found correlated with academic self-handicapping the strongest $[3,4]$. Notwithstanding this direction, the type and intensity of association between personality and academic self-handicapping might be different from the findings that were provided by the past research due to the cultural and environmental differences. A study, therefore, was designed to investigate the predictive relationship between personality traits and academic self-handicapping with self-esteem as the mediator in the Malaysian context. The intake of self-esteem as a mediator was planned due to the imminent correlation between the academic self-handicapping and self-esteem $[2,4]$. In definition, self-esteem is an individual judgment of personal worth or value, and its self-evaluative component has been derived from the comparison of real self and ideal self [5].

\section{Literature Review}

\subsection{Overview of Academic Self-Handicapping}

Heeding the call to promote higher academic performance and positive learning attitudes among students in tertiary education, academic self-handicapping has been intensively inspected as a function of personality traits and self-esteem [2]. According to Kinon and Murray [4], this debilitating attitude is referred as a self-defeating behavior that makes an individual to underachieve the goal. Apparently, academic self- handicapping has long been a protector against threatening self-esteem [4], and further slowing down the process of learning and improving [6]. To perform academic self-handicapping, individual may demonstrate behaviors such as procrastinating tasks, claiming sickness and weak, as well as requesting to withdraw from the assignments [7].

\subsection{Academic Self-Handicapping in Educational Setting}

University is widely known as a highly evaluative, competitive and stressful environment. The undergraduates need to complete countless of assignments, sit for multiple 
tests and examinations throughout the degree years. Furthermore, it is undeniable that parents, lecturers and third party will evaluate the competency of students based upon the academic performance. Covington [8] stated that academic performance may play the role as indication of ability. In the competitive academic setting, rewards are usually linked to excellent academic performance [9]. It is important to note that academic self-handicapping tends to occur in evaluative and competitive situations [10] and undergraduates seem to extensively employ self- handicapping strategies [11]. The past research findings revealed that procrastination is one of the major self-handicapping strategies utilized by students. Hill, Hill, Chabot, and Barrall [12] indicated that there was around $70 \%$ of college students suffered from academic procrastination, and approximately $95 \%$ of the college students who seem to procrastinate in the academic tasks [13]. Likewise, Onwuegbuzie [14] mentioned that graduate students possessed high level of procrastination.

\subsection{Academic Self-Handicapping Strategies}

Insomuch as a common strategy, self-handicapping has habitually been utilized by students in the academic settings [15]. It is a self-defeating behavior that leads to academic underachievement among the college students [16]. Berglass and Jones [6] defined self-handicapping as "creating or claiming an impediment to one's performance, which can be cited as an excuse for failure". On the point of a manifest, this detrimental tactics may include behaviors such as procrastinating, making up excuses, putting less effort in completing tasks, selecting tough goals [17], engaging in too many activities at a time, choosing not to seek for necessary help, giving up easily, claiming test anxiety and illness, having inadequate sleep as alibi, drinking alcohol or taking drugs before examination $[5,18]$.

\subsection{The Roles of Academic Self-Handicapping}

Owing to the failure of performing optimally under the pressure of assessment [19], students might thereupon adopt self-handicapping strategies to cope with time management problem, intellectual challenges, and performance challenges in the academic setting. These academic circumstances could be overwhelming or fatiguing [15]. Furthermore, some previous researches showed that self-handicapping plays the role in protecting the self-esteem of an individual and it serves as a presentation strategy to manipulate others' perceptions $[8,20]$. Self-handicap intentionally creates obstacles to success so that this individual is able to cast about for pretext for failure over lack of ability. The obstacles enable individual to discount the responsibility for failure and augment credit for success [21], undertaking well as a defense mechanism to protect one's self-esteem when facing with potential failure in the academic settings. In consummation, self-handicapping abides to externalize failure and internalize success [6].

\subsection{Types of Self-Handicapping}

Probing the categorization of self-handicapping, the two cardinal types are behavioral self-handicapping and self-reported self-handicapping. Individual who utilizes behavioral self-handicapping vigorously will be developing a disadvantage condition prior to an evaluation. The strategies utilized by behavioral self-handicaps include not practicing prior to an evaluation, consuming alcohol. On the other hand, individual who utilizes self-reported self-handicapping vigorously states that a disadvantageous condition is present prior to an evaluation [22] such as claiming test anxiety, illness, in bad mood, side effects of medication and physical, psychological or emotional symptoms. As compared with self-reported self-handicapping, behavioral self-handicapping is much more detrimental and dangerous because the strategies used by behavioral self-handicaps seem to dwindle the actual feasibility for success [23].

\subsection{Personality and Self-Handicapping}

In addition to the detrimental effect, self-handicaps perceived that protecting oneself from the negativity of failure is more crucial than gaining success [24], and this perception leads to the temptation of doing self-handicapping behaviors [9]. Moreover, intense self-handicapping behavior may accelerate the adopting of self-handicapping strategy as the self-handicap doubts about his or her abilities [25].

As a matter of course, no exclusive variable could be a definable causation to a manifestation. Kinon and Murray [4] found that there was a positive relationship between self-handicapping and neuroticism. In contrary, there was a negative relationship between self-handicapping and openness, conscientiousness, agreeableness. Bobo, Whitaker, and Strunk [3] revealed that both of the personality traits of conscientiousness and neuroticism were significantly predicting self-handicapping. This finding was backed by the findings of Ross, Canada, and Rausch [26] interpreting that lower conscientiousness predicted higher self-handicapping. Besides that, higher neuroticism seemed to predict higher self-handicapping. However, up to date, there is no research conducted to identify the predictive relationship of personality traits of openness, neutral, analytical, relational and decisive on academic self-handicapping. Thus, the current research aims to fill in this research gap by predicting the academic self-handicapping using the personality traits comprising openness, neutral, analytical, relational and decisive.

\subsection{Self-Esteem and Self-Handicapping}

In distinction to the interaction between personality traits and self-handicapping, previous research in like manner revealed that students who are lower in self-esteem seem to possess higher self-handicapping tendencies [4, 27]. Individual who has low level of self-esteem tends to elicit response to protect oneself from the consequences of failure [21]. Besides, Martin and Brawley [28] discovered that there were significant negative relationships between temptation to self-handicapping and likelihood of self-handicapping with general and physical self-esteem among the athletes. 
Based upon the necessity of doing this study to know more about the connection among personality, self-esteem and academic self-handicapping behavior following literature review, two hypotheses were formulated including (1) Relational personality is the strongest predictor for academic self-handicapping; (2) There is a significant mediating effect of self-esteem in the relationship between personality and academic self-handicapping.

\section{Methods}

\subsection{Participants}

A sample of 62 bachelor's degree psychology students from a private university has been invited as participants for the study. Of the 62 participants, 43 of them were females. All participants were ethically recruited based upon their willingness to participate in this study.

\subsection{Instruments}

Leonard Personality Inventory (LPI). LPI consisted of 100 items. It was systematically developed by Yong [29] based on the Five Factor Model to provide the information of an individual's personality traits encompassing openness, neutral, analytical, relational and decisive [29]. This tool has been further administered on online basis that is user-friendly enough to be employed. The higher the score of a personality trait describes the greater tendency of possessing this particular trait for an individual. Yong [57] has conducted a study on 78 managers in manufacturing corporations with the purpose of examining the reliability of the Leonard Personality Inventory, and the finding showed moderately high internal reliability for the five personality traits, ranging from .71 to .80 in alpha coefficient.

Academic Self-Handicapping Scale (ASHS). This six-item assessment tool was developed by Midgley and Urdan [30] to measure self-handicapping behavior according to the three features essential for the item pertaining to the measured construct [18]. Hence, the items are entailing the priori timing of strategy, procrastinating action as well as giving reason for the handicapping behavior [18]. In using this scale, participants are required to rate describing themselves on a five-point likert scale ranging from 'Not at all true' to 'very true'. As a result, the higher the score obtained through this scale represents the higher of the self-handicapping tendency [31]. With respect to psychometric properties of the Academic Self-Handicapping Scale, meta-analysis by Schwinger, Lemmer, Wirthwein and Steinmayr [56] has concluded that the divergent validity of the Academic Self-Handicapping Scale is sufficient through the findings showing academic self-handicapping behavior was significantly associated with academic achievement. Schwinger, Lemmer, Wirthwein and Steinmayr [56] mentioned that the reliability of the Academic Self-Handicapping Scale has considerably influenced the correlation between self-handicapping behavior and achievement.

Rosenberg's Self-Esteem Scale (RSES). RSES that consisted of 10 items with 4-point likert scale has been developed to assess respondent's self-confidence and self-deprecation [32]. Respondent with higher score of RSES was regarded as higher in self-esteem. According to the findings shown by Hatcher and Hall [54], Rosenberg's Self Esteem Scale has demonstrated adequate internal consistency with alpha coefficient of .83, and sufficient validity with strong negative relationship to depressive symptoms and destructive thought. In addition, study by Aluja, Rolland, Garcia and Rossier [55] using Rosenberg's Self-Esteem Scale and NEO Personality Inventory showed that self-esteem was correlated strongly with neuroticism and moderately with extraversion and conscientiousness.

\subsection{Procedures}

During a semester, the identified group of bachelor's level Psychology students was systematically approached in their classrooms. In giving the instructions before administrating the surveys, respondents were explicitly promised the confidentiality of their responses, and that only group means rather than individual scores were used in analyses. Informed consent was obtained from each participant before the questionnaire was distributed. Each group of respondents was given ample time to complete the questionnaire. Data have been collected continuously over an approximately 2-week period.

\subsection{Data Analysis}

Following data gathering and logging, Analysis of Moment Structures (AMOS) was used to perform outputs by means of the functions of multiple regression as well as counting of path coefficients respectively.

\section{Results}

Throughout a series of statistical analyses, the findings of the current study have presented that, among the five personality traits, academic self-handicapping has remarkably been predicted by neutral personality, $\mathrm{B}=-.25, \mathrm{p}<0.05$, which was not expected in hypothesis formation. As depicted in Fig. 1, this negative relationship illustrated that higher neutral personality predicted lower academic self-handicapping in the sample.

Nevertheless, the aforementioned significant Beta coefficient does not reflect significant relationship between these two variables when the mediation model was examined, for the reason that the mediating investigation has been operated in a separate manner for every personality trait instead of inspecting all the five traits in a mediation model. This effort is to ensure that the other traits were controlled while a particular trait was tested for more precise mediating relationship. Hence, the Beta coefficient in the Figure 1 could be different from that in the mediation model. 


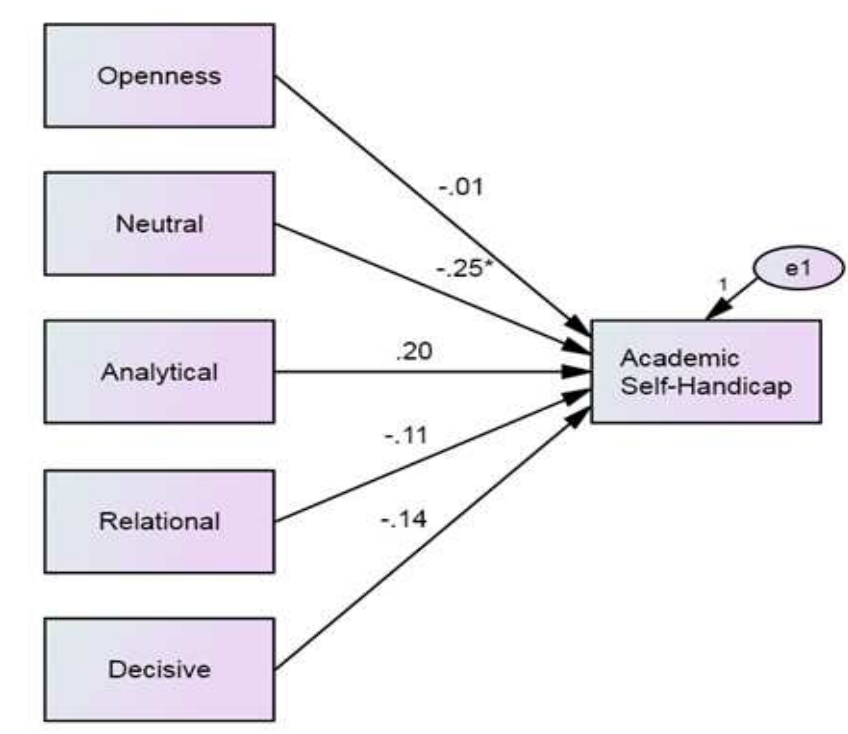

Notes. ${ }^{*} \mathrm{p}<0.05$

Figure 1. Path diagram for the predictive relationship between personality traits and academic self-handicapping.

Beyond the predictive relationship inspection, the mediating role of self-esteem has carefully been tested and found that it has representatively mediated the relationship between personality and academic self-handicapping in the research sample (Fig. 2 - Fig. 6). Among the five personality traits, this significant role is wholly valid on the type of relational personality as portrayed in Fig. 5. Entering of self-esteem as the mediator variable has comprehensively eliminated the significant coefficient in between relational personality and academic self-handicapping, $B=-.25, p<0.05$, to $\mathrm{B}=-.09, \mathrm{p}>0.05$. The paths from this relational personality to the mediator self-esteem, and sequential to academic self-handicapping are essential with $\mathrm{B}=.46, \mathrm{p}<0.05$ and $\mathrm{B}=$ $-.35, p<0.05$ respectively. As a result, the mediating effect of self-esteem in the relationship between personality and academic self-handicapping is partially significant as it is solely applicable to relational personality trait.

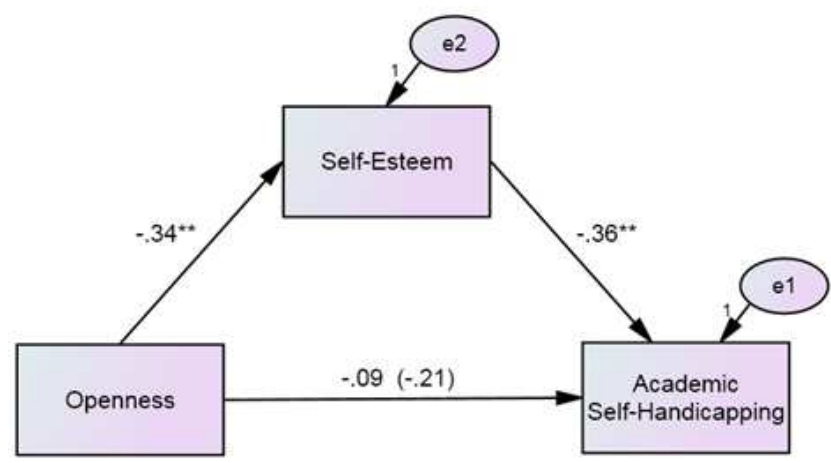

Figure 2. Path diagram for the mediation model of self-esteem in the relationship between openness and academic self-handicapping.

Notes. ${ }^{* *} \mathrm{p}<0.01$; Standardized Beta coefficient before the entering of mediator is shown in the parenthesis.

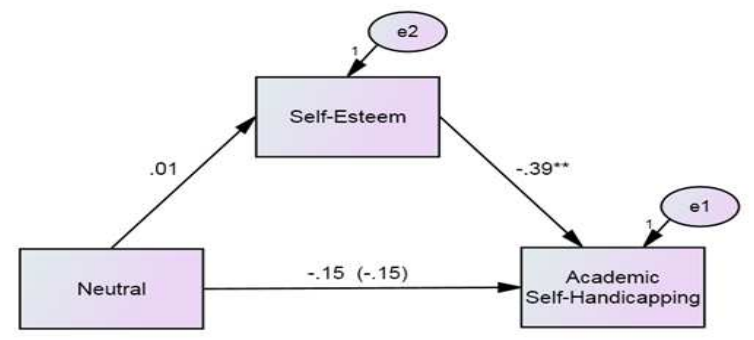

Figure 3. Path diagram for the mediation model of self-esteem in the relationship between neutral and academic self-handicapping.

Notes. ${ }^{* *} \mathrm{p}<0.01$; Standardized Beta coefficient before the entering of mediator is shown in the parenthesis.

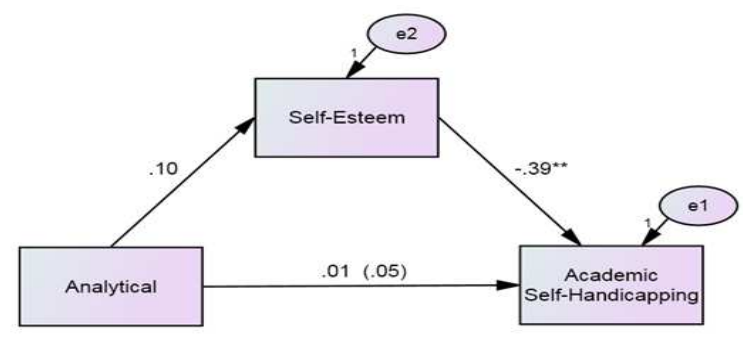

Figure 4. Path diagram for the mediation model of self-esteem in the relationship between analytical and academic self-handicapping.

Notes. ${ }^{* *} \mathrm{p}<0.01$; Standardized Beta coefficient before the entering of mediator is shown in the parenthesis.

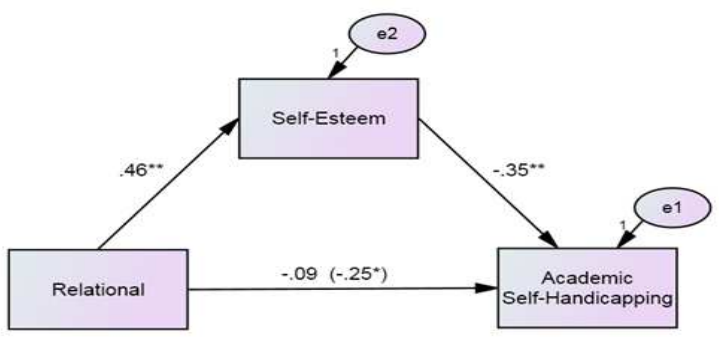

Figure 5. Path diagram for the mediation model of self-esteem in the relationship between relational and academic self-handicapping.

Notes. ${ }^{* *} \mathrm{p}<0.01$; Standardized Beta coefficient before the entering of mediator is shown in the parenthesis.

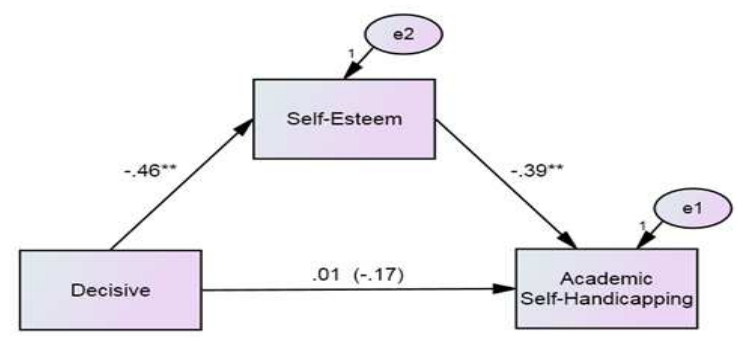

Figure 6. Path diagram for the mediation model of self-esteem in the relationship between decisive and academic self-handicapping.

Notes. ${ }^{* *} \mathrm{p}<0.01$; Standardized Beta coefficient before the entering of mediator is shown in the parenthesis. 


\section{Discussion and Conclusion}

In consonance with the statistical analyses, neutral personality has exhibited its convincing predictive association with the variable of academic self-handicapping. This is consistent with the findings demonstrated in the study by Felder, Felder, and Dietz [33] which indicated that those students with perceiving personality trait in Myers-Briggs types have knowingly underperformed compared to judging type in encountering heavy demand on curriculum in university setting. Perceiving type of personality is given description as the enduring characteristic of having tendency in preferring flexibility and spontaneity in handling daily tasks [33]. Hence, academic self-handicapping could be one of the strategies for these students to protect themselves [34] and is a way to manipulate their impressions from other people [35].

Given that personality has been inclusive of three components of social skills, self-image and relationship between one self and its environment [36], it is quite seemingly interpreted that interaction between one self and surroundings is a conceivable part of the contributions to produce one's personality traits. Therefore, the characteristic of non-judging in neutral personality could contribute to adverse relationship by any means with academic self-handicapping strategies which emphasize the bringing about of others' impressions [35]. On the contrary, Cloninger, Svrakic, and Przybeck [37] claimed that personality is made of elements encompassing harm avoidance, this element may have great predictive power to the tendency of avoiding or delaying task accomplishments among students. The explanation given by Cloninger, Svrakic, and Przybeck [37] shows the association between personality and academic self-handicapping strategies in university setting. This kind of association has indisputably been endorsed by the findings of Debra, Jonathan, and Thomas [38] demonstrating that motivation to learn is predictive of personality traits. Nevertheless, these personality traits are solely limited to openness and extraversion in contrast to the neutral type in the current research.

Felder, Felder, and Dietz [33] proposed that assessing students' learning styles could be operated through administrating personality traits assessment. This assessment of personality traits can reflect students' academic strengths, skills, interest and so on. For this reason, personality traits have anticipatorily been corresponded to academic self-handicapping strategies in this study, and with other 'self' variables such as self-esteem as well as subjective well-being [20,39].

Having reinforcement from abundant research findings elucidating that self-esteem has meaningfully mediated the association between social related variables and mental health [40 - 45], the mediating role of self-esteem from the present study was confidently demonstrated in the connection between personality and attitudes on task accomplishment in academic setting among students. This remarkable character of self-esteem is purely functional to relational personality in its predictive association with academic self-handicapping strategies. This finding is consistent with the past research findings expressing the importance of human interaction contributing to the level of one's self-esteem $[46,47,48]$.

By materializing the aforesaid evidences on the vital association between social variables and self-esteem, the representation of mediator on self-esteem in the predictive relationship between relational personality and academic self-handicapping strategies could mirror the need for social interaction among university students. This social interaction might contribute to the intension of their self-esteem and shrinkage of the tendency to externalize failures in academic task accomplishment. In other words, being self-handicapping in doing academic tasks might be an indirect manifestation of acquiring low self-esteem over possessing insufficiently high relational trait in personality. This kind of compensative relationship can be contemplated by the findings of Pulford, Johnson, and Awaida [49] which proved that self-handicaps tend to carry low self-esteem.

In spite of the short term benefits of adopting self-handicapping strategies [20], the long term costs of adopting self-handicapping strategies may incorporate lower self-esteem, academic dissatisfaction, academic underachievement, lower adjustment, lower self-regulation, lower subjective well-being, a loss in competence satisfaction, increase in negative mood and increase in self-reported consumption of substances [20,21,39]. Urdan [50] found that self-handicapping tends to indicatively predict the deterioration in academic achievement [50]. These high self-handicaps perform poorly owing to procrastination and insufficient study [51]. Thus, self-handicapping can be considered as a maladaptive coping strategy.

Prior to the performance, individuals with high self-handicapping were inclined to view the task to be important and relevant to themselves [17]. These individuals are uncertain about their own abilities and skills [22], and subsequently want to protect their self-worth [9,39]. It is paramount to note that the indication of ability is a principle aspect of self-worth [8] in which skepticism on one's own ability will lead to ambiguity of self-worth. Thus, protecting self-worth is very essential for certain students [9]. The pre-established excuses aim to safeguard the person from the negativity over a performance [52].

In the academic settings, there are many students who strive hard to avoid being identified as "stupid" by others. Self-handicapping provides a proper alibi in the situation whereby the students incline to perform sickly [8]. As a deduction, students make use of various self-handicapping strategies to rationalize the ill performance [53]. In the similar manner, there are many people striving to maintain positive self-evaluation. Yet, the individuals might utilize self-handicapping strategy to secure the positive self-evaluation while facing the circumstances with little chance to succeed [6].

Taken together, this present study has implicated that relational personality trait is evident in contributing to different levels of self-esteem and self-handicapping behaviors in academic tasks among university students. 
Magnifying relational trait in personality might be one of the indirect alternatives in diminishing the task avoidance or delaying attitudes in academic setting. Following this contemplation, self-worth among students has been playing a crucial role in not only affecting their psychological well-being at their adolescence stage but as well their attitudes and behaviors driving them to task accomplishments.

More research on personality traits and academic self-handicapping strategies should be conducted to report findings on its relationship among students for the purpose of aiding them in learning more rapidly and efficiently, and driving them towards progressive and higher academic achievement.

\section{References}

[1] Milgram, N., \& Tenne, R. (2000). Personality correlates of decisional and task avoidant procrastination. European Journal of Personality, 14, 141-156.

[2] Owens, A. M., \& Newbegin, I. (2000). Academic procrastination in adolescents in English and Mathematics: Gender and personality variations. Journal of Social Behavior and Personality, 15(5), 111-124.

[3] Bobo, J. L., Whitaker, K. C., \& Strunk, K. K. (2013). Personality and student self-handicapping: A cross-validated regression approach. Manuscript.

[4] Kinon, M. D., \& Murray, C. B. (2007). A profile of the college self-handicapper. Undergraduate Research Journal, 13-17.

[5] Alesi, M., Rappo, G., \& Pepi, A. A. (2012). Self-esteem at school and self-handicapping in childhood: Comparison of groups with learning disabilities. Psychological Reports: Disability \& Trauma, 111(3), 952-962.

[6] Berglass, S., \& Jones, E. E. (1978). Drug choice as a self-handicapping strategy in response to noncontigent success. Journal of Personality and Social Psychology, 36, 405-417.

[7] Schwinger, M., Wirthwein, L., Lemmer, G., \& Steinmayr, R. (2014). Academic self-handicapping and achievement: A meta-analysis. Journal of Educational Psychology, 1, 1-18.

[8] Covington, M. V. (1992). Making the grade: A self-worth perspective on motivation, and school reform. New York: Cambridge University Press.

[9] Martin, A. J., Marsh, H. W., Williamson, A., \& Debus, R. L. (2003). Self-handicapping, defensive pessimism and goal orientation: a qualitative study of university students. Journal of Educational Psychology, 95(3), 617-628.

[10] Kearns, H., Forbes, A., Gardiner, M., \& Marshall, K. (2008). When a high distinction isn't good enough: A review of perfectionism and self-handicapping. The Australian Educational Researcher, 35(3), 21-36.

[11] Ellis, A., \& Knaus, W. J. (1977). Overcoming procrastination. New York: Institute for Rational Living.

[12] Hill, M. B., Hill, D. A., Chabot, A. E., \& Barrall, J. F. (1978). A survey of college faculty and student procrastination. College Student Journal, 12, 256-262.

[13] Steel, P. (2007). The nature of procrastination: A meta-analytic and theoretical review of quintessential self-regulatory failure. Psychological Bulletin, 8, 454-458.

[14] Onwuegbuzie, A. J. (2004). Academic procrastination and statistics anxiety. Assessment \& Evaluation in Higher Education, 29(1), 3-19.

[15] Strube, M. J. (1986). An analysis of the self-handicapping scale. Basic and Applied Social Psychology, 7(3), 211-224.

[16] Greene (2002). High school graduation rates in the United States. Retrieved May 3, 2007, from http://www.manhattaninstitute.org $/ \mathrm{html} / \mathrm{cr}$ _baeo.htm

[17] Greenberg, J. (1985). Unattainable goal choice as a self-handicapping strategy. Journal of Personality and Social Psychology, 15, 140-152.

[18] Urdan, T., \& Midgley, C. (2001). Academic self-handicapping: What we know, what more there is to learn. Educational Psychology Research, 13, 115-138.

[19] Thomas, T., \& Dinnel, D. L. (2007). Is self-worth protection best regarded as intentional self-handicapping behaviour or an outcome of choking under pressure? Educational Psychologist, 27(4), 509-531.

[20] McCrea, S., \& Hirt, E. (2001). The role of ability judgments in self-handicapping. Personality and Social Psychology Bulletin, $27,1378-1389$

[21] Zuckerman, M., Kieffer, S. C., \& Knee, C. R. (1998). Consequences of self-handicapping: Effects on coping, academic performance, and adjustment. Journal of Personality and Social Psychology, 74, 1619-1628.

[22] Snyder, C. R., Smith, T. W., Augelli, R. W., \& Ingram, R. E. (1985). On the self-serving function of social anxiety: Shyness as a self-handicapping strategy. Journal of Personality and Social Psychology, 48(4), 970-980.

[23] Coudevylle, G. R., Martin Ginis, K. A., \& Famose, J. P. (2008). Determinants of self-handicapping strategies in sport and their effects on athletic performance. Social Behavior and Personality, 36, 391-398.

[24] Murray, C., \& Warden, R. (1992). Implications of self-handicapping strategies for academic achievement: A reconceptualization. Journal of Social Psychology, 132, 23-37.

[25] Bailis, D. S. (2001). "Benefits of self-handicapping in sport: A field study of university athletes." Canadian Journal of Behavioural Science, 33, 213-23.

[26] Ross, S. R., Canada, K. E., \& Rausch. (2002). Self-handicapping and the five factor model of personality: Mediation between neuroticism and conscientiousness. Personality and Individual Differences, 32, 1173-1184.

[27] Pullmann, H., \& Allik, J. (2008) Relations of academic and general self-esteem to school achievement. Personality and Individual Differences, 45, 559-564.

[28] Martin, K. A., \& Brawley, L. R. (2002). Self-handicapping in physical achievement settings: The contributions of self-esteem and self-efficacy. Psychology Press, 1, 337-351.

[29] Yong, M. S. (1999). The LEONARD Personality Inventory. Petaling Jaya: Nemo Marketing.

[30] Midgley, C., \& Urdan, T. (1995). Predictors of middle school students' use of self-handicapping strategies. The Journal of Early Adolescence, 15, 389-411 
[31] Gadbois, S. A., \& Sturgeon, R. D. (2011). Academic self-handicapping: Relationships with learning specific and general self-perceptions and academic performance over time. British Journal of Educational Psychology, 81(2), 207-222.

[32] Rosenberg, M. (1965). Society and the adolescent self-image. Princeton, New Jersey: Princeton University Press.

[33] Felder, R. M., Felder, G. N., \& Dietz, E. J. (2002). The effects of personality type on Engineering student performance and attitudes. Journal of Engineering Education, 64(3), 273-286.

[34] Thomas, C. R., \& Gadbois, S. A. (2007). Academic self-handicapping: The role of self-concept clarity and students' learning strategies. British Journal of Educational Psychology, 77, 101-119.

[35] Midgley, C., Arunkumar, R., \& Urdan, T. C. (1996). "If I don’t do well tomorrow, there's a reason": Predictors of adolescents' use of academic self-handicapping strategies. Journal of Educational Psychology, 88(3), 423-434.

[36] Yildirim, S., \& Çam, O. (2002). Nursing academicians' attitudes towards work life and their personality traits. Journal of Psychiatric and Mental Health Nursing, 19(8), 709-714.

[37] Cloninger, C. R., Svrakic, D. M., \& Przybeck, T. R. (1993). Psychobiological model of temperament and character. Archives of General Psychiatry, 50, 975-990.

[38] Debra, A. M., Jonathan, E. T., \& Thomas, D. F. (2006) Linking proactive personality and the Big Five to motivation to learn and development activity. Journal of Applied Psychology, 91(4), 927-935

[39] Zuckerman, M., \& Tsai, F. F. (2005). Costs of self-handicapping. Journal of Personality, 73, 411-442.

[40] An, J., An, K., O'Connor, L., \& Wexler, S. (2008). Life satisfaction, self-esteem, and perceived health status among elder Korean women: Focus on living arrangements. Journal of Transcultural Nursing, 19, 151-160.

[41] Cheng, S. K., \& Fatimah, Y. (2010a). Investigating the moderating and mediating effects of dysfunctional attitudes and self-esteem on the relationship between social support and depression among late adolescents in Klang Valley Malaysia: A moderated mediation model. International Journal of Education and Information Technologies, 2(4), 73-82.

[42] Cheng, S. K., \& Fatimah, Y. (2010b). Roles of dysfunctional attitudes and self-esteem in the relationship between social support and depression in late adolescence (pp. 39-44). Proceedings of the WSEAS International Conference on Sociology, Psychology, Philosophy, Penang, Malaysia.

[43] Taylor, R. D., Budescu, M., \& McGill, R. K. (2011). Demanding kin relations and depressive symptoms among low-income African American women: Mediating effects of self-esteem and optimism. Cultural Diversity and Ethnic Minority Psychology, 17(3), 303-308.

[44] Kapikiran, S. (2013). Loneliness and life satisfaction in Turkish early adolescents: The mediating role of self-esteem and social support. Social Indicators Research, 111(2), 617-632.
[45] Zou, J. (2014). Associations between trait emotional intelligence and loneliness in Chinese undergraduate students: Mediating effects of self-esteem and social support. Psychological Reports, 114(3), 880-890.

[46] Tian, L., Liu, B., Huang, S., \& Huebner, E. (2013). Perceived social support and school well-being among Chinese early and middle adolescents: The mediational role of self-esteem. Social Indicators Research, 113(3), 991-1008.

[47] Bednar, R. L., Wells, M. G., \& Petersen, S. R. (1989). Self-esteem: paradoxes and innovations in clinical theory and practice. Washington: American Psychological Association.

[48] Cohen, S., \& Syme, S. L. (1985). Issues in the study and application of social support. In S. Cohen \& S. L. Syme (Eds.), Social support and health (pp. 3-22). Orlando, Florida: Academic Press Inc.

[49] Pulford, B. D., Johnson, A., \& Awaida, M. (2005). A cross cultural study of predictors of self-handicapping in university students. Personality and Individual Differences, 39, 727-737.

[50] Urdan, T. (2004). Predictors of self-handicapping and achievement: Examining achievement goals, classroom structures, and culture. Journal of Educational Psychology, 96, $251-264$.

[51] Beck, B. L., Koons, S. R., \& Milgrim, D. L. (2000) Correlates and consequences of behavioral procrastination: the effects of academic procrastination, self-consciousness, self-esteem, and self-handicapping. Journal of Social Behavior and Personality, 15(5), 3-13.

[52] Snyder, C. R., \& Smith, T. W. (1982). Symptoms as self-handicapping strategies: The virtues of old wine in a new bottle. In G. Weary \& H. L. Mirels (Ed.), Integrations of clinical and social psychology (pp. 104-127). New York: Oxford University Press.

[53] Akca, F. (2012). An investigation into the self-handicapping behaviors of undergraduates in terms of academic procrastination, the locus of control and academic success. Journal of Education and Learning, 1(2), 288-297

[54] Hatcher, J., \& Hall, L. A. (2009). Psychometric properties of the Rosenberg Self-Esteem Scale in African American single mothers. Issues in Mental Health Nursing, 30(2), 70-7.

[55] Aluja, A., Rolland, J. P., García, L. F., \& Rossier, J. (2007). Dimensionality of the Rosenberg Self-Esteem Scale and its relationships with the three- and the five-factor personality models. Journal of Personality Assessment, 88(2), 246-9.

[56] Schwinger, M., Lemmer, G., Wirthwein, L., \& Steinmayr, R. (2014). Academic Self-Handicapping and Achievement: A Meta-Analysis. Journal of Educational Psychology, 106(3), 744-761.

[57] Yong, L. M. S. (2003). Norms and technical manual: The Leonard Personality Inventory (LPI). Kuala Lumpur: Leonard Personality Incorporated Sdn Bhd. 